Egyptian

Orthodontic Journal

\title{
DIMENSIONAL CHANGES OF THE DENTAL ARCHES: CROSS SECTIONAL STUDY FROM 8 TO 14 YEARS IN A SAMPLE OF YEMENI CHILDREN
}

\author{
Riyadh A. Iskander ${ }^{1}$, Nabil El-Desouky Abu-Shamaah², \\ Ahmed Abdel-Fattah Ramadan ${ }^{3}$
}

\section{ABSTRACT}

Introduction: Orthodontists can benefit from understanding occlusal changes during every stage of human development. The growth and development period is influenced by environmental factors, nutrition, and ethnic variations; systemic health and individual variations can also occur. The aim in this study was to study the changes in the dental arch dimensions with age from mixed dentition to early permanent dentition in a group of Yemeni school pupils. Methods: One hundred and Twenty subjects (60 females, 60 males) divided into three groups Gp1 (8- Cess than 10 yrs), GP2 (10 - less than 12 yrs) and GP3 (12 -14 yrs). Vpper $\mathcal{L}$ lower study casts were evaluated in centric occlusion. The casts were scanned and 9 parametrs; arch perimeter, arch length, inter-canine width, inter-molar width, and palatal depth; were measured on the computed cast images by using special software. In addition 2 parameters; overjet and overbite; were measured manually. Results: The maxillary arch perimeter showed gender effect at GP3; however, the other parameters there were no gender effect. There were significant changes in arch perimeters, arch length, overbite, and palatal depth in Yemeni school pupils

1- Postgraduate Orthodontics student, Faculty of Dentistry, Suez Canal University, Egypt.

2- Assistant professor of Orthodontics, Faculty of Dentistry, Suez Canal University., Egypt.

3- Professor of Orthodontics, Faculty of Dentistry, Suez Canal University, Egypt. 
Egyptian

Orthodontic Journal

between the mixed and the permanent dentitions. Conclusions: These results should be useful in planning orthodontic treatment for Yemeni patients in the mixed and early permanent dentition.

Key words: arch dimension, Yemeni population, digital measurement.

\section{INTRODUCTION}

The dental arches are defined as the composite structure of the dentition and the alveolar ridge. They show many morphological changes in size and relationship from birth to the completion of permanent dentition.

Dental arch dimensions involving teeth diameters, arch lengths, arch widths, arch depths and arch forms have long been an area of great interest to orthodontics. As growth takes place, the dental arch shows great variation in respect to width, length and perimeter to end up in a well-aligned and established occlusion that satisfies both esthetics and function. Also, information concerning these dimensions in different human populations is of great importance to clinicians in diagnosis and treatment planning. Studying the developmental changes, abnormal timing or order of eruption and extrinsic factors affecting the individual tooth position can help in understanding and solving orthodontic problems. Analysis of the developmental changes that occur in the dental arch while growth takes place, especially between the late mixed dentition and the early permanent one, is one of the most important aspects in clinical orthodontics. This certainly affects the efficiency of diagnosis and treatment planning.

Changes that occur during growth and development, especially during the transformation from mixed to permanent dentition, and the application of such analyses using geometric methods for describing the different arch dimensions while growth takes place seems to be very beneficial.

This article focuses on several important factors related to the general effect of orthodontic treatment and normal growth on arch width. Arch 
dimensions change with growth ${ }^{(1)}$; therefore, it is necessary to distinguish changes induced by appliance therapy from those that occur as a result of natural growth. Naturally occurring changes in untreated persons should be used as the gold standard for evaluating dental arch changes produced by orthodontic treatment ${ }^{(2)}$.

Many studies have investigated arch dimensional changes in various stages of the growth and development period: arch dimensions, ${ }^{(3,4,5,6,7,8,9)}$ Yet, few studies including all those parameters evaluated the transition from the mixed to the permanent dentition ${ }^{(5,8)}$.

The aim of the present study was to study the changes in the dental arch dimensions with age from mixed dentition to early permanent dentition in a group of Yemeni pupils.

\section{MATERIALS AND METHODS}

This study was carried out on 120 Yemenis pupils, of both sexes, their ages ranged from 8-14 years. This sample was selected from 13 primary schools in Ibb governorate-Yemen country. One hundred and Twenty subjects (60 females, 60 males) with complete records from the early mixed dentition (GP1), late mixed dentition (GP2) and the early permanent dentition (GP3) stages were included in this study (total, 240 dental casts).

All subjects of this study were selected to have Yemeni parents, age ranging from eight to fourteen years (from mixed dentition to early permanent dentition), clinically normal (judged) occlusion, without midline shift, no malformed teeth, no habits present, and no previous orthodontic treatment.

The selected sample consisted of 120 subjects divided into 3 equal groups $(n=40)$ according to their chronological ages and each group consisted of (20 males and 20 females). The age by which the three groups were classified was as follows: GP1 ranging from 8 to $<10$ years, GP2 from 10 to $<12$ years, and GP3 from 12 to 14 years.

Alginate impressions, occlusion registration in centric relation by wax bites blocks, and stone plaster casts were prepared for each subject 
(GP1, GP2 and GP3) and occlusion was taken in centric relation by wax bites blocks. Each model was identified and coded before scanning to have an indirect digital image. The different dental arch dimensional parameters (arch perimeter, arch length, inter-canine width, inter-molar width, and palatal depth) were measured and calculated by special software program ${ }^{*}$. The overjet and overbite were measured manually. Each cast was measured at 3 different occasions, and the mean values were recorded.

The following parameters were measured from each tooth to its corresponding antimere (fig.1): (1) Maxillary arch perimeter, from the mesiobuccal cusp tip of the maxillary first permanent molar on one side passing through cusp tip and incisal edges of the anterior teeth, (2) Maxillary inter-canine width, from the cusp tip of the maxillary canine, (3) Maxillary inter-molar width, from the mesiobuccal cusp tip of the maxillary first permanent molars, (4) Mandibular arch perimeter, from the mesiobuccal cusp tip of the mandibular first permanent molar on one side passing through cusp tip and incisal edges of the anterior teeth, (5) Mandibular inter-canine width, from the cusp tip of the mandibular canine, (6) Mandibular inter-molar width, from the mesiobuccal cusp tip of the mandibular first permanent molars, (7) Maxillary arch length, from the maxillary inter-incisal point located at midpoint between the mesial surfaces of maxillary central incisors-to the mid distance of the line tangent to the distal surfaces of maxillary first molars, (8) Mandibular arch length, from the mandibular inter-incisal point located at midpoint between the mesial surfaces of mandibular central incisors to the mid distance of the line tangent to the distal surfaces of mandibular first molars, (9) Palatal depth, from the deepest point in the palate to the line connecting central fossae of maxillary first molars on both sides (fig.2). While the following parameters were measured manually, (10) Overjet as a horizontal measurement referring to the distance between the labial surface of the maxillary incisors and the labial surface of the mandibular incisors when the teeth are in centric occlusion, (11) Overbite as a vertical measurement in percentage coverage of the lower incisors by the upper incisors when teeth were in centric occlusion.

\footnotetext{
* Digora for Windows 2.5 Rev 2, Dental Imaging Software, SOREDEX, FINLAND.
} 


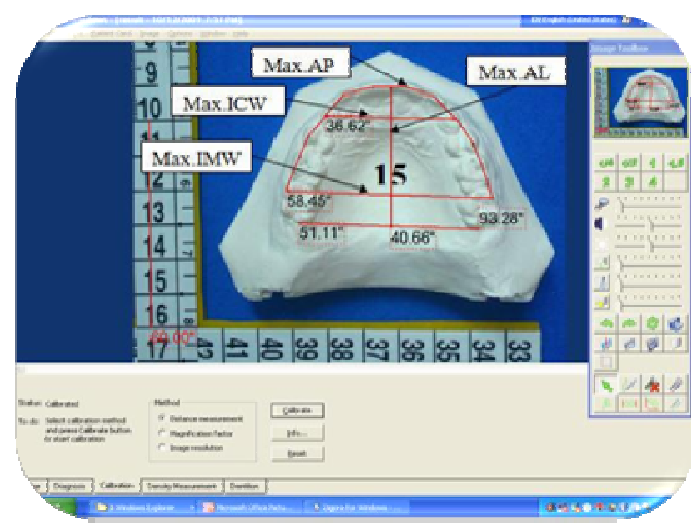

Figure (1): maxillary arch parameters measurement.

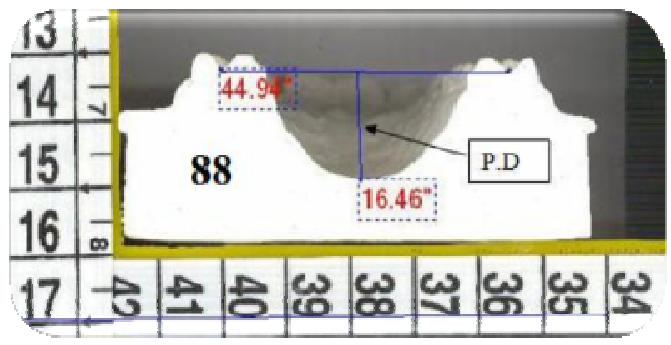

Figure (2): palatal depth measurement.

\section{Statistical analysis}

Statistical assessment was carried out using SPSS version 16.0 for windows (Statistical Package for Social Sciences, Ill, USA) program.

Descriptive statistics including mean and standard deviation were computed for each parameter in male and female groups. Non parametric Independent sample t-test was used to test the effect of the sex difference on all parameters. Parametric ANOVA test was used to test the change between different age groups.

\section{RESULTS}

When the sexes were compared at GP1, GP2, and GP3 no statistically significant gender effect was found in all parameters (table 1 and 2) except in maxillary arch perimeter at GP3. 
Egyptian

Orthodontic Journal

Table 1: comparison of arch parameters between males and females at GP1 and GP2 ( $\mathrm{t}$ test results)

\begin{tabular}{|l|c|c|c|c|c|c|c|c|c|c|c|c|}
\hline \multirow{2}{*}{$\begin{array}{c}\text { Measurements } \\
(\mathrm{mm})\end{array}$} & \multicolumn{2}{|c|}{$\begin{array}{c}\text { Male } \\
(\mathrm{GP} 1)\end{array}$} & \multicolumn{2}{c|}{$\begin{array}{c}\text { Female } \\
(\mathrm{GP} 1)\end{array}$} & & & \multicolumn{2}{c|}{$\begin{array}{c}\text { Male } \\
(\mathrm{GP} 2)\end{array}$} & \multicolumn{2}{c|}{$\begin{array}{c}\text { Female } \\
(\mathrm{GP} 2)\end{array}$} & & \\
\cline { 2 - 14 } & Mean & SD \pm & Mean & SD \pm & P & Sig. & Mean & SD \pm & Mean & SD \pm & P & Sig. \\
\hline Max.AP & 83.67 & 3.48 & 83.46 & 2.67 & .836 & NS & 82.67 & 3.21 & 80.85 & 4.05 & .123 & NS \\
\hline Mand.AP & 75.15 & 3.44 & 74.29 & 2.61 & .377 & NS & 72.33 & 4.02 & 71.94 & 3.94 & .757 & NS \\
\hline Max.AL & 38.09 & 1.94 & 38.11 & 1.64 & .975 & NS & 38.20 & 1.84 & 38.01 & 2.37 & .780 & NS \\
\hline Mand.AL & 34.61 & 1.88 & 34.66 & 1.41 & .916 & NS & 33.83 & 1.84 & 34.47 & 3.66 & .496 & NS \\
\hline Max.ICW & 33.04 & 1.56 & 32.50 & 1.39 & .263 & NS & 32.63 & 1.75 & 33.03 & 2.32 & .542 & NS \\
\hline Mand.ICW & 26.46 & 1.65 & 25.57 & 1.57 & .088 & NS & 25.53 & 1.55 & 25.70 & 1.40 & .726 & NS \\
\hline Max.IMW & 49.84 & 1.93 & 48.64 & 2.07 & .065 & NS & 50.58 & 2.53 & 49.40 & 2.81 & .170 & NS \\
\hline Mand.IMW & 44.25 & 1.94 & 43.12 & 1.82 & .063 & NS & 43.71 & 2.45 & 43.66 & 2.53 & .946 & NS \\
\hline O.B & 2.73 & .83 & 2.43 & .65 & .214 & NS & 2.48 & .678 & 2.40 & .66 & .725 & NS \\
\hline O.J & 3.78 & 1.07 & 3.23 & .658 & .058 & NS & 3.45 & .84 & 3.59 & .97 & .641 & NS \\
\hline P.D & 14.44 & 1.74 & 13.82 & 2.15 & .320 & NS & 15.18 & 1.82 & 14.71 & 1.74 & .413 & NS \\
\hline
\end{tabular}

NS: not significant at $5 \%$ level of confidence $(\mathrm{P} \leq .05)$

AP: Arch perimeter AL: Arch length ICW: Inter-canine width IMW: Inter-molar width

P.D: palatal depth Max:Maxillary Mand:Mandibular O.J:Overjet

O.B:Overbite

Descriptive statistics and ANOVA test results of the measurements change from the total group at GP1, GP2 and GP3.

There were statistically significant differences in arch perimeter during the transition from mixed to permanent dentition in all groups (table 3).

Statistically significant decreases were found between GP2 and GP3 in male maxillary arch length, while in the mandibular arch length statistically significant decreases were found between GP2 and GP3 in male length while in female the significant decreases were found between GP1 and GP3 (table 3).

Regarding the maxillary and mandibular inter-canine width only significant decrease was found in male mandibular inter-canine width between the GP1 and GP3 (table 3).

The inter-molar width both maxillary and mandibular the significant change was found only between GP1 and GP3 in female maxillary inter-molar width (table 3 ). 
In case of overjet there is no any change among all age groups of both sexes.

On the other hand, statistically significant decreases were found in the overbite between GP1 and GP3 in both males and females. At another parameter as palatal depth increased from GP1 to GP3 in both sexes.

Table 2: comparison of arch parameters between males and females at GP3 (t test results)

\begin{tabular}{|l|c|c|c|c|c|c|c|}
\hline \multirow{2}{*}{\multicolumn{1}{|c|}{ Measurements (mm) }} & \multirow{2}{*}{$\mathrm{N}$} & \multicolumn{2}{c|}{ Male (GP3) } & \multicolumn{2}{c|}{ Female (GP3) } & \multirow{2}{*}{$\mathrm{P}$} & \multirow{2}{*}{ Sig. } \\
\cline { 3 - 6 } & & Mean & $\mathrm{SD} \pm$ & Mean & $\mathrm{SD} \pm$ & & \\
\hline Maxillary arch perimeter & 20 & 79.76 & 3.74 & 77.19 & 2.46 & $.014 *$ & $\mathrm{~S}$ \\
\hline Mandibular arch perimeter & 20 & 68.44 & 3.10 & 68.12 & 3.40 & .762 & $\mathrm{NS}$ \\
\hline Maxillary arch length & 20 & 36.56 & 1.50 & 36.68 & 2.43 & .859 & $\mathrm{NS}$ \\
\hline Mandibular arch length & 20 & 32.35 & 1.36 & 32.59 & 1.89 & .641 & $\mathrm{NS}$ \\
\hline Maxillary intercanine width & 20 & 33.04 & 1.91 & 32.95 & 1.65 & .867 & $\mathrm{NS}$ \\
\hline Mandibular intercanine width & 20 & 25.09 & 1.73 & 25.69 & 1.34 & .228 & $\mathrm{NS}$ \\
\hline Maxillary intermolar width & 20 & 50.42 & 2.85 & 50.48 & 2.19 & .940 & $\mathrm{NS}$ \\
\hline Mandibular intermolar width & 20 & 43.51 & 2.85 & 43.81 & 1.82 & .698 & $\mathrm{NS}$ \\
\hline Overbite & 20 & 2.45 & .510 & 2.53 & .75 & .714 & $\mathrm{NS}$ \\
\hline Overjet & 20 & 2.23 & .57 & 2.28 & .58 & .785 & $\mathrm{NS}$ \\
\hline Palatal Depth & 20 & 16.30 & 2.75 & 16.41 & 1.89 & .882 & $\mathrm{NS}$ \\
\hline
\end{tabular}

NS: not significant at $5 \%$ level of confidence $(\mathrm{P} \leq .05)$

Table 3: Changes in arch parameters at different Male and Female groups

\begin{tabular}{|l|c|c|c|c|c|c|}
\hline \multirow{2}{*}{} & \multicolumn{3}{|c|}{ Male } & \multicolumn{3}{c|}{ Female } \\
\cline { 2 - 7 } & GP1 & GP2 & GP3 & GP1 & GP2 & GP3 \\
\hline Max. arch perimeter & $\mathrm{a}$ & $\mathrm{a}$ & $\mathrm{b}$ & $\mathrm{a}$ & $\mathrm{b}$ & $\mathrm{c}$ \\
\hline Mand. arch perimeter & $\mathrm{a}$ & $\mathrm{b}$ & $\mathrm{c}$ & $\mathrm{a}$ & $\mathrm{b}$ & $\mathrm{c}$ \\
\hline Max. arch length & $\mathrm{a}$ & $\mathrm{a}$ & $\mathrm{b}$ & $\mathrm{a}$ & $\mathrm{a}$ & $\mathrm{a}$ \\
\hline Mand. arch length & $\mathrm{a}$ & $\mathrm{a}$ & $\mathrm{b}$ & $\mathrm{a}$ & $\mathrm{ab}$ & $\mathrm{b}$ \\
\hline Max. inter-canine width & $\mathrm{a}$ & $\mathrm{a}$ & $\mathrm{a}$ & $\mathrm{a}$ & $\mathrm{a}$ & $\mathrm{a}$ \\
\hline Mand. inter-canine width & $\mathrm{a}$ & $\mathrm{ab}$ & $\mathrm{b}$ & $\mathrm{a}$ & $\mathrm{a}$ & $\mathrm{a}$ \\
\hline Max. inter-molar width & $\mathrm{a}$ & $\mathrm{a}$ & $\mathrm{a}$ & $\mathrm{a}$ & $\mathrm{ab}$ & $\mathrm{a}$ \\
\hline Mand. Inter-molar width & $\mathrm{a}$ & $\mathrm{a}$ & $\mathrm{a}$ & $\mathrm{a}$ & $\mathrm{a}$ & $\mathrm{a}$ \\
\hline Overjet & $\mathrm{a}$ & $\mathrm{a}$ & $\mathrm{a}$ & $\mathrm{a}$ & $\mathrm{a}$ & $\mathrm{a}$ \\
\hline Overbite & $\mathrm{a}$ & $\mathrm{a}$ & $\mathrm{b}$ & $\mathrm{a}$ & $\mathrm{a}$ & $\mathrm{b}$ \\
\hline Palatal Depth & $\mathrm{b}$ & $\mathrm{ab}$ & $\mathrm{a}$ & $\mathrm{b}$ & $\mathrm{b}$ & $\mathrm{a}$ \\
\hline
\end{tabular}

$\mathrm{dt}=$ Duncan's Multiple Range Test for the effect of age groups.

Means with the same letter within each row are not significantly different at $\mathrm{p}=0.05$. 
Egyptian

Orthodontic Journal

\section{DISCUSSION}

Study of criteria for different ethnic groups is essential to promote accurate diagnosis and planning for orthodontic treatment. Each ethnic group has certain characteristics that should not be taken as standards for other areas with different development and ecological foundations.

The developmental changes that occur in the dental arch while growth takes place, especially between the late mixed dentition and the early permanent one, are aspects of importance in clinical orthodontics. In this study the mixed dentition stage of development was chosen because it corresponds to the time when early orthodontic therapy might be started in patients with severe malocclusion. So, understanding the normal changes among Yemenis children (pure Yemenis parents) will be beneficial to understand and solve many orthodontic problems in this area.

The computer generated dental arch image as a tool for measurement most certainly will become routine practice in orthodontic because it will substitute manual measures. It is accurate, fast, easy retrievable data and solving the problem of dental cast storage ${ }^{(10)}$.

For precise and accuracy in taking the measurements all the study models were scanned (1:1) in order to reach high reliability. The later was verified by choosing commonly used landmarks, gaining experience the program used by many trials and checking out the measurement by inter-examiners which in turn raise the value of the informative data.

The current study revealed that the gender effect on all arch parameters except the maxillary arch perimeter in GP3 were insignificant. This result was in disagreement with Hassanali and Odhiambo ${ }^{(11)}$, and Arslan et $\mathrm{al}^{(12)}$, which could be attributed to different genetic and ethnic basis. The genetic backgrounds have an obvious effect in the inter-canine widths in both sexes and among all groups.

Regarding the calculation of arch perimeter there was significant decrease except from GP1 to GP2 in maxillary arch. This decrease might be related to the mesial shifting of the first molars to leeway spaces. This finding is in agreement with Moorrees ${ }^{(13)}$, Bishara et al. ${ }^{(14)}$, and Sinclair ${ }^{(15)}$. Also, there is significant decrease in mandibular arch length in males from GP3 to other groups and in females from GP1 to GP3. These results could be explained as a direct reflection to the decrease of arch perimeter.

Volume 36-December 2009 
Egyptian

Orthodontic Journal

This findings are in agreement with Slaj ${ }^{(16)}$. who claimed that the arch perimeters decreased between the ages of 9 and 14years due to changes in the dentition.

The result of the present study showed that the inter-canine width remained unchanged significantly from age 8 to 14 years in both sexes except mandibular inter-canine width was decreased significantly from GP1 to GP3 in males. This result was in agreement with Sillman ${ }^{(6)}$ while, disagreement with Sampson and Richards ${ }^{(17)}$ who reported increase in the inter-canine widths among Yuendumu population sample. This could be explained on the basis of difference genetic factor.

Intermolar width has commonly been used as a measure of posterior arch dimension. In females there is little decrease from GP1 to GP2 and little increase from GP2 to GP3. Both are insignificant at $(\mathrm{P} \leq .0 .05)$. The later is in agreement with the results of Sinclaire and Little ${ }^{(8)}$, while in male group there are insignificant changes among all groups on both arches. This un notable changes in all groups in both sexes and arches might be explained as the inter-molar width remains stable.

The insignificant change of the overjet was in agreement with Sinclair and Little ${ }^{(8)}$ and disagreed with Arslan et al. ${ }^{(16)}$ and Moorrees ${ }^{(5)}$ that have shown specific trends in the changes noted for overjet. These differences could be related to the method of study, the present study was designed to be cross sectional type of study, while other studies were longitudinal type of study.

The overbite significantly decreased this finding was in agreement with Bjork ${ }^{(18)}$

The method used in this study to measure the palatal depth digitally, but in two dimensional way; has been created from the idea of direct three dimensional scanning. In this research a new method to measure palatal depth has been designed to overcome this point. It is essential to use an appropriate soft ware to have accurate measurement.

The significant increased in the palatal depth is in agreement with Bjork and Skieller ${ }^{(19)}$ and Redman et $\mathrm{al}^{(20)}$. This increase might be attributed to the increase in the alveolar height accompanying eruption of both maxillary and mandibular permanent teeth and to compensate for the vertical growth of the ascending ramus ${ }^{(21)}$. 
Egyptian

Orthodontic Journal

\section{CONCLUSIONS}

From the results obtained from this study, the following can be concluded:

a. No gender effect was present in all dental arch parameters except in maxillary arch perimeter at (12-14years) age group.

b. The means of all arch parameters in males were higher than females in all age groups.

c. There were significant changes in arch perimeter, arch length, overbite and palatal depth in all age groups.

d. The inter-canine width, inter-molar width and overjet were remained unchanged significantly from age 8 to 14 years in both sexes.

e. The overbite is significantly decreased from age 8years to age 14 years.

\section{REFERENCES}

1. Bishara SE, Jakobsen JR, Treder J, Nowak A. Arch width changes from 6 weeks to 45 years of age. Am J Orthod Dentofacial Orthop 1997;111:401-9.

2. Carter GA, McNamara JA Jr. Longitudinal dental arch changes in adults. Am J Orthod Dentofacial Orthop 1998;114:88-99.

3. Bishara SE, Bayati P, Zaher AR, Jakobsen JR. Comparisons of the dental arch changes in patients with Class II, division 1 malocclusions: extraction vs nonextraction treatments. Angle Orthod 1994;64:351-8.

4. Barrow CG, White JR. Developmental changes of the maxillary and mandibular dental arches. Angle Orthod 1952;22:41-6.

5. Moorrees CFA. The dentition of the growing child. Cambridge, Mass: Harvard University Press; 1959.

6. Sillman JH. Dimensional changes of the dental arches: longitudinal study from birth to 25 years. Am J Orthod 1964;50:824-42.

7. Lundstrom A. Changes in crowding and spacing of the teeth with age. Dent Pract Dent Rec 1969;19:218-24. 
8. Sinclair PM, Little RM. Maturation of untreated normal occlusions. Am J Orthod 1983;83:114-23

9. Bishara SE, Jakobsen JR, Treder JE, Stasi MJ. Changes in the maxillary and mandibular tooth-size arch length relationship from early adolescence to early adulthood. A longitudinal study. Am J Orthod Dentofacial Orthop 1989;95:46-59.

10. Alcan T, Ceylanoglu C, Baysal B. The Relationship between Digital Model Accuracy and Time-Dependent Deformation of Alginate Impressions. Angle Orthod 2009;79:30-36.

11. HassanaIi J, Odhiambo JW. Analysis of dental casts of 6-8 and 12-year-old Kenyan children. Eur J Orthod 2000; 22:135-142.

12. Arslan SG, Kama JD, Şahin S, Hamamci O. Longitudinal changes in dental arches from mixed to permanent dentition in a Turkish population. Am J Orthod Dentofacial Orthop 2007;132:576.e 15-576.e21.

13. Moorrees CFA. The dentition of the growing child. Cambridge, Mass: Harvard University Press; 1959.

14. Bishara SE, Jakobsen JR, Treader J, Nowak A. Arch length analysis from 6 to 45 years. Angle Orthod 1998; 68: 69-74

15 . Sinclair PM, Little RM. Maturation of untreated normal occlusions. Am J Orthod 1983;83:114-23

16. Slaj M, Marina JA., Lauc T, Meštrovic SR, Mikši M. Longitudinal Dental Arch Changes in the Mixed Dentition. Angle Orthod 2003; 73:509-514.

17. Sampson WJ, Richards LC. Prediction of mandibular incisor and canine crowding changes in mixed dentition. Am J Orthod 1985;88:47-63.

18. Bjork A. Variability and age changes in overjet and overbite. Am J Orthod 1953;39:774-801. 
19. Bjork A, Skieller V. Growth of the maxilla in three dimensions as revealed radiographically by the implant method. Br J Orthod 1976; 4:53-64.

20. Redman R.S, ShapiroB.L, Gorlin R.J. Measurement of normal and reportedly malformed palatal vaults. II: Normal juvenile measurements. J Dent Res 1966; 45:266-269.

21. William, H. Determining the shape of the normal arch. Dent Cosmos 1917;59:695-708. 